University of Arkansas, Fayetteville

ScholarWorks@UARK

Education Reform Faculty and Graduate

Students Publications

Education Reform

6-1-2015

\title{
The Intergenerational Transmission of Noncognitive Skills and Their Effect on Education and Employment Outcomes
}

\author{
Ildefonso Mendez \\ University of Murcia
}

Gema Zamarro

University of Arkansas, Fayetteville, gzamarro@uark.edu

Follow this and additional works at: https://scholarworks.uark.edu/edrepub

Part of the Educational Assessment, Evaluation, and Research Commons, Educational Leadership Commons, and the Other Educational Administration and Supervision Commons

\section{Citation}

Mendez, I., \& Zamarro, G. (2015). The Intergenerational Transmission of Noncognitive Skills and Their Effect on Education and Employment Outcomes. Education Reform Faculty and Graduate Students Publications. Retrieved from https://scholarworks.uark.edu/edrepub/45

This Article is brought to you for free and open access by the Education Reform at ScholarWorks@UARK. It has been accepted for inclusion in Education Reform Faculty and Graduate Students Publications by an authorized administrator of ScholarWorks@UARK. For more information, please contact scholar@uark.edu. 


\section{USCDornsife}

Center for Economic

and Social Research

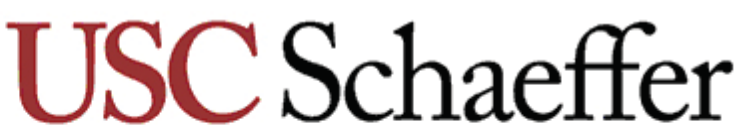

Leonard D. Schaeffer Center for Health Policy \& Economics

\section{The Intergenerational Transmission of}

Noncognitive Skills and Their Effect on Education and Employment Outcomes

Ildefonso Mendez, Gema Zamarro

Paper No: 2015-015

\section{CESR-SCHAEFFER WORKING PAPER SERIES}

The Working Papers in this series have not undergone peer review or been edited by USC. The series is intended to make results of CESR and Schaeffer Center research widely available, in preliminary form, to encourage discussion and input from the research community before publication in a formal, peerreviewed journal. CESR-Schaeffer working papers can be cited without permission of the author so long as the source is clearly referred to as a CESR-Schaeffer working paper. 


\title{
The intergenerational transmission of noncognitive skills and their effect on education and employment outcomes
}

\author{
Ildefonso Mendez* \\ University of Murcia \\ Gema Zamarro \\ University of Arkansas \& University of Southern California
}

June 2015

\begin{abstract}
We use information on second-generation migrants to study the existence of a cultural component on the formation process of noncognitive skills and its effect on education and employment outcomes. Our measures of noncognitive skills include: personality traits that children are encouraged to learn and civic capital. Individuals whose cultural heritage places a lower value on child qualities positively associated to the conscientiousness personality factor report lower education, worse occupational status and lower wages on average. Individuals with a higher inherited civic capital declare a higher educational level, but we find no effect of civic capital on adult labor market outcomes.
\end{abstract}

Keywords: culture, civic capital, child qualities, non-cognitive skills, education, employment.

JEL Classification: I2, J24, Z1.

*This research was supported by the Fundación Ramón Areces. Contact author: Ildefonso Mendez. E-mail: ildefonso.mendez@um.es. Mailing address: Departamento de Economía Aplicada, Facultad de Economía y Empresa, 30100, Espinardo (Murcia), Spain. Phone: +34 868883732. Fax: +34 868883745. 


\section{Introduction}

A growing literature shows that individual skills like perseverance, self-control or social competence play a prominent role on life-time outcomes like education, employment, and health outcomes, even after controlling for individual differences in cognitive ability (Almlund et al., 2011). These skills, along with similar others, are labelled "noncognitive skills" and they appear to be, for some collectives, even more relevant predictors of observed individual differences in life-time outcomes than innate intellectual ability (Almlund et al., 2011, Lindqvist and Vestman, 2011).

Most of what economists know about the technology of noncognitive skill formation concerns early educational levels. Cunha and Heckman (2008) show that cognitive and noncognitive skills are jointly determined by parental environments and investments at different stages of childhood. They find that parental investments are more effective in raising noncognitive skills and that noncognitive skills promote the formation of cognitive skills, while causality does not run in the opposite direction. Additionally, the evidence reviewed in Heckman and Kautz (2013) shows that noncognitive skills can also be enhanced in a lasting and cost-effective way by means of high-quality early childhood and elementary school programmes. As Brunello and Schlotter (2011) pointed out in their literature review, more research is needed in this area to further learn about the origin of noncognitive skills.

In this paper we aim to contribute to the literature on noncognitive skills by analyzing the existence of a cultural component on its formation process and by testing for its effects on education and employment outcomes in adulthood. We do so by testing whether country differences in the qualities that children are encouraged to learn at home or in the value placed on public goods, i.e. differences in culture, lead to country differences in educational attainment and employment outcomes in adulthood.

Culture is an ambiguous word. We define culture as the set of beliefs and preferences that conditions individuals' actions, that systematically vary across either socially or geographically defined groups and that are transmitted to successive generations (Fernandez and Fogli, 2009). Since the effect of culture cannot be separately identified from 
those of economic and institutional factors in a between-country analysis, we use the socalled "epidemiological approach" (Fernandez, 2008). This identification strategy takes advantage of the differential "portability" of culture relative to economic and institutional factors. The idea is that when individuals emigrate, they may take some of the predominant beliefs and preferences from their birthplace with them and transmit them intergenerationally. Thus, noncognitive traits may also vary across second-generation immigrant groups reflecting culture in their country of origin. These second-generation migrants, born and raised in the same country, face the same markets and institutions, but their cultural heritage is likely to differ according to their parents' country of birth.

By studying education and labor performance of second generation migrants, this paper also contributes to the literature by testing to what extend observed differences in socio-economic status of second generation migrants across different countries of ancestry (see, e.g., Chiswick and DebBurman, 2004 for an overview of this literature) might be due to cultural differences on the relevance of certain noncognitive skills children are encouraged to learn at home. For instance, Asians are often found to outperform other groups in educational attainment (Hirschman and Wong, 1986; Lee and Rong, 1988) while students of Hispanic origin often present lower achievement levels and higher dropout rates, compared to Asians and non-Hispanic whites (Arias, 1986; Velez, 1989).

For this aim, we use pooled 2005-2012 March Current Population Survey (CPS) data to obtain information on American second-generation immigrants' educational attainment and labor market outcomes. Additionally, we use the first two waves of the World Values Survey (WVS), carried out around 1981 and 1990, respectively, to approximate respondents' cultural heritage. In particular, we obtain a first set of cultural proxies based on responses of respondent's country of ancestry about which child qualities they considered to be in the group of the five most important for children to learn at home. There were eleven child qualities respondents from the WVS could choose from: good manners; independence; feeling of responsibility; hard work; imagination; tolerance; thrift; perseverance; religious faith; unselfishness and obedience.

Mendez (2015) showed that country differences in the noncognitive skills or qualities that children are encouraged to learn at home, i.e. differences in culture, account for 
international differences in 15 years old student's performance in the PISA study. In particular, he found that a one-standard-deviation increase in culture accounted for between $10 \%$ and $30 \%$ of the standard deviation of student performance across ancestries, depending on the particular subject and host country considered. This paper builds on this work to analyze the effect of differences in culture on education and labor outcomes in adulthood.

In contrast with Mendez (2015), in this paper we also analyze the relevance of the noncognitive skills embodied in the concept of civic capital, introduced in Guiso, Sapienza and Zingales (2010) and defined as the set of beliefs and values that help cooperation in society. Guiso, Sapienza and Zingales (2010) showed that civic capital is differentiated from human capital, that it satisfies the properties of the standard notion of capital, and that it helps to explain why differences in economic performance across countries persist over centuries. In this work, the authors obtain a synthetic measure of civic capital as the first principal component of the variation across ancestries of the responses to four questions of the WVS where respondents were asked to tell how justifiable the following behaviors were: "Claiming government benefits to which you are not entitled", "Avoiding a fare on public transport", "Cheating on taxes if you have a chance" and "Accepting a bribe in the course of their duties".

Our goal in this paper is to test for the relevance of the intergenerational transmission of the noncognitive skills described above in determining adults' education and employment outcomes. When doing so, we pay particular attention to the interdependencies between the two synthetic cultural measures considered, obtained by using principal components analysis. In interpreting our results, we make use of the correspondence described in Mendez (2015) between these child qualities and the five personality factors in the "Big Five", the most influential taxonomy of personality skills, to compare our results to those in the economic and psychological literatures. In this paper we also discuss how we think the concept of civic capital relates to the different dimensions of the Big Five.

Our estimates suggest that the intergenerational transmission of certain noncognitive skills plays a prominent role in determining individuals' educational level and employ- 
ment status during adulthood. In particular, we find that individuals whose cultural heritage considers the qualities positively associated to the conscientiousness personality factor, like thrift and particularly so hardworking, as higher valued qualities to encourage in children have higher educational levels and, in particular, are more likely to complete college after finishing high school. Additionally, we find that the lower the weight a respondent's cultural heritage places on hard work and thrift, the lower the probability that he/she is in a high-skilled occupation if employed (i.e. management, business and financial occupations or professional and related occupations). Also, if the weight placed on hard work and thrift is lower, the probability that he/she earns a higher wage is also lower, but only for wages above the median of the wage distribution. These findings are in line with the large body of evidence summarized in Almlund et al. (2011) showing that personality measures related to the conscientiousness personality factor, like hardworking, predict educational attainment and other outcomes in adulthood.

Regarding civic capital, we find that individuals with a higher inherited civic capital also have higher educational levels and a higher probability of completing college after finishing high school, although the latter effect is lower than that estimated for the transmission of child qualities associated to constientiousness. However, we do not find an effect of inherited civic capital on employment outcomes, once educational attaintment is controlled for. This, in turn, suggests that a certain level of both inherited civic capital and hardworking (conscientiousness) are relevant for educational success whereas only the inherited stock of conscientiousness matters for achieving success in the labor market.

These estimates provide a lower bound on the effect of the intergenerational transmission of noncognitive abilities on education and employment outcomes, since the epidemiological approach tends to underestimate the effect of culture. As Fernandez and Fogli (2009) argue, first-generation immigrants may not hold the preferences and values that are representative of their country's culture. Moreover, although analyzing the second instead of the first-generation of immigrants has the advantage of minimizing group differences due to language barriers, it also means that the impact of culture from the source country is likely to have been attenuated over time. 
The outline of the rest of the paper is as follows. Sections 2 reviews the relevant literature. Section 3 presents the empirical strategy and datasets used to identify the effect of culture on adult outcomes while Section 4 presents and discusses the estimation results. Finally, Section 5 presents the main conclusions of our work.

\section{A Brief Literature Review}

The idea that culture affects individual behavior goes back to at least Max Weber who, in his classical work "The Protestant Ethic and the Spirit of Capitalism" (Weber, 1905), argued that a particular culture, the "Protestant Ethic", supported by Reformation teachings that the pursuit of wealth was a duty, played a major role in the development of capitalism. The economic literature has developed the tools for showing, in a quantitative fashion, that culture matters. We now have an operational definition of culture (Fernandez and Fogli, 2009), and an identification strategy, the so-called epidemiological approach (Fernandez, 2008), that separatelly identifies the effect of culture from those of market variables and institutions by studying the behavior of second-generation immigrants of different origins living in the same host country. Our paper belongs to this literature that empirically tests the cultural hypothesis.

There is evidence that culture affects relevant economic outcomes like, among others: female work and fertility (Fernandez and Fogli, 2009), trust and trade (Guiso, Sapienza and Zingales, 2009), economic growth (Guiso, Sapienza and Zingales, 2010, Tabellini, 2010), children's living arrangements (Giuliano, 2007), employment patterns of different demographic groups (Algan and Cahuc, 2005), the design of labor market institutions (Algan and Cahuc, 2006), gender roles (Alesina, Giuliano and Nunn, 2011), home production, female labor force participation and geographical mobility (Alesina and Giuliano, 2010), risk and trust attitudes (Dohmen et al., 2012), and achievement in test scores (Mendez, 2015). ${ }^{1}$

This literature uses quantitative variables measured in the second-generation immi-

\footnotetext{
${ }^{1}$ See Fernandez (2011) and Guiso, Sapienza and Zingales (2006) for an exhaustive review of the relevance of culture for economic outcomes.
} 
grant's country of ancestry as a proxy for culture. Although these aggregate variables reflect country differences in economic, institutional and cultural factors, the only reason why they might affect the behavior of second-generation immigrants, born and raised in a different country, is because of their cultural component. It is also common to perform factor analyses to extract principal components as composited measures of cultural variables if there are several cultural indicators available. That is the approach, among others, in Alesina and Giuliano (2010), Guiso, Sapienza and Zingales (2010), Tabellini (2010), and it is also the approach we take in this paper since we have, on the one hand, evaluations of eleven child qualities in the respondent's country of ancestry and, on the other hand, four indicators of civic capital, as proxies for our two cultural measures. Moreover, the papers just cited above, as ours, use the World Values Survey to obtain their cultural indicators.

Our paper also belongs to an even more recent literature on the economic consequences of individual character skills. The review in Almlund et al. (2011) shows that other skills different from cognitive ability affect economic outcomes like achievement test scores, educational attainment, employment and health status in adulthood. These skills are often labelled "noncognitive skills" and they include attributes, dispositions, social skills, attitudes, and intrapersonal resources, independent of intellectual ability (U.S. Department of Education, 2013).

Noncognitive skills appear to be, for some collectives, even more relevant predictors of observed individual differences in life-time outcomes than innate intellectual ability. Lindqvist and Vestman (2011) find, using data from the Swedish military enlistment on cognitive and noncognitive skills, based on personal interviews conducted by psychologists, that noncognitive skills are more strongly associated with labor market outcomes for the top of the earnings distribution. At the same time, they find that cognitive skills are a stronger predictor of wages for skilled workers and of earnings above the median. Almlund et al. (2011) show that personality skills, and in particular those related to the conscientiousness personality factor ("the tendency to be organized, responsible, and hardworking"), are stronger predictors of variation in longevity and achivement test scores than innate intellectual ability. 
In a related setting, Guiso, Sapienza and Zingales (2010) introduced the concept of civic capital, defined as the set of beliefs and values that promote cooperation in society. They showed that such a noncognitive skill is differentiated from human capital, that it satisfies the properties of the standard notion of capital and that it helps to explain why differences in economic performance across countries persist over centuries. However, they do not control for country differences in the relevance of other noncognitive skills, like the personality traits embodied in the child qualities included in the WVS, for example.

We aim at analyzing whether the intergenerational transmission of the noncognitive skills resumed in the child qualities listed in the WVS and in the concept of civic capital introduced in Guiso, Sapienza and Zingales (2010) affect individuals' adult education levels and employment outcomes.

\section{Methodology and datasets}

To analyze the effect of culture on adult outcomes we use the following linear regression model:

$$
y_{i j t}=\beta_{0}+\beta_{1} X_{i t}+\delta_{1} \widetilde{Z}_{1 j}+\delta_{2} \widetilde{Z}_{2 j}+\lambda_{t}+\varepsilon_{i j t},
$$

where $y_{i j t}$ is the adult outcome, i.e. educational attainment, employment status, or earnings if employed, of individual $i$, of ancestry $j$, interviewed in year $t$. The cultural

proxies $\widetilde{Z}_{1 j}$ and $\widetilde{Z}_{2 j}$ control for the intergenerational transmission of child qualities and civic capital, respectively. Equation (1) is estimated by ordinary least squares using the sample of second-generation immigrants living in the U.S. To control for the fact that the unobservables $\left(\varepsilon_{i j t}\right)$ might be correlated across individuals from a given ancestry, we computed clustered-robust standard errors where we interpret each ancestry as a cluster. This is a relevant issue since the outcome variable varies at the individual level but our cultural proxies do so only at the country-of-ancestry level. ${ }^{2}$

\footnotetext{
${ }^{2}$ As shown in Hansen (2007), the clustered covariance matrix is valid for inference when the number of clusters is large and the size of the clusters is fixed, as it is the case in our application since we have 36 clusters of fixed size.
} 
The cultural proxies, used in the analysis, are based on data from the first two waves of the WVS, that were carried out around 1981 and 1990, respectively. These years were chosen to approximately represent the time were the parents of the second generation migrants in our sample were living in the country of ancestry. We pooled data from these two waves together in order to attain a sufficiently large number of ancestries, as not all waves of the WVS included information of the same countries. The variable $\widetilde{Z}_{1 j}$ is obtained from the responses to the following question: "Here is a list of the qualities that children can be encouraged to learn at home. Which, if any, do you consider to be specially important? Please choose up to five". There were eleven child qualities in the list: good manners; independence; feeling of responsibility; hard work; imagination; tolerance and respect for other people; thrift, sparing money and things; perseverance; religious faith; unselfishness and obedience. Since respondent's evaluations of the different child qualities are correlated across respondents and ancestries, we use principal components factor analysis to construct index measures for our cultural variable $\widetilde{Z}_{1 j}$ based on this information.

Following Guiso, Sapienza and Zingales (2010), the variable $\widetilde{Z}_{2 j}$ is obtained as the first principal component of a factor analysis of the responses to four questions of the WVS where respondents were asked to tell how justifiable the following behaviors were: "Claiming government benefits to which you are not entitled", "Avoiding a fare on public transport", "Cheating on taxes if you have a chance" and "Accepting a bribe in the course of their duties". Responses ranged from 1 to 10, where 1 and 10 meant that such behavior was "never justifiable" or "always justifiable" for the respondent, respectively. To make these variables reflect increases in civic capital, we recoded them so that 10 means "never justifiable" and 1 "always justifiable". 3

\footnotetext{
${ }^{3}$ According to Guiso, Sapienza and Zingales (2010) there are seven questions in the WVS that capture how much people value public goods and, thus, can be used to proxy for the relevance of civic capital in a country. These questions include the four we considered in the analysis, as well as the respondent's agreement with the following behaviors: "Lying on your own interest", "Throwing away litter in a public space" and "Speeding over the limit in built up areas". However, all these questions were not asked in all the waves of WVS and so, we do not use the latter three variables since they are not available for most countries in our sample. Equivalently, the single index of civic capital obtained in Guiso, Sapienza and Zingales (2010) only considers three (claim government benefits, cheat on taxes and accept a bribe) out of the four variables used in our application.
} 
Our empirical analysis is then peformed on the pooled 2005-2012 March Current Population surveys (CPS). After 1994, the March CPS informs on the place of birth of each respondent and his parents. We pool the March CPS from 2005 to 2012 to increase the sample size of second-generation immigrants. For our main sample we consider a respondent to be a second generation migrant if he/she was a native-born individual with an immigrant father. ${ }^{4}$ Our analysis focuses on respondents aged 25 to 35 years old since most of them have already finished their formal education. We do not consider older individuals since the hypothesis that our cultural measures were recorded in the respondent's country of ancestry at the time his father lived there would not be very realistic. For the same reason we do not use CPS data collected before 2005. ${ }^{5}$

We study five different outcome variables of interest. Firstly, we analyze whether the intergenerational transmission of noncognitive skills affects respondent's educational attainment and, in particular, the probability of them continuing studying and obtaining a college degree after having finished high school. Secondly, we study the effect of culture on the likelihood of having a job, of being a high-skilled worker, i.e. of working in the first two major occupational groups (managers, business and financial occupations and professional and related occupations), as well as its effects on wages for those in the labor force, after controlling for occupational status.

We control for the following individual and family characteristics included in $X$ : the respondent's gender, age, age squared, perceived health status, marital status, number of children under six years of age in the household and per-capita family income excluding respondent's wage and salary earnings. For married respondents, we also control for his spouse's immigration status (first, second-generation or none of them), employment status and educational level (less than high school, high school, some college and college degree). All the estimates control for interview year, state of residence and metropolitan

\footnotetext{
${ }^{4}$ We also explored alternative definitions based on having an immigrant mother instead and results were similar to the ones presented in this paper. The alternative of requiring two immigrant parents for a native-born individual to be classified as second-generation lead to a much smaller sample size.

${ }^{5}$ In our CPS sample respondents were born between 1970 and 1987 and the waves of the WVS used to obtain the cultural proxies were carried out in 1981 and 1990. Obviously, the match is not perfect but it is likely to provide a reasonable approximation to ideal conditions since culture is found to be a slow moving institution (Roland, 2004).
} 
area effects.

To better interpret our results, in the context of the recent literature on noncognitive skills, it is worth to establish a correspondence between the noncognitive skills, which intergenerational transmission is analyzed in this paper, and the personality factors in the "Big Five", since most results in the literature are referred to that taxonomy of personality skills. The "Big Five", derived from factor analysis of measurements of personality from different sources comprises the following personality factors: Conscientiousness (C), Openness to Experience (O), Extraversion (E), Agreeableness (A) and Neuroticism (N). Table 1 defines the five personality factors and resumes the expected correspondence between the child qualities in the WVS and the personality factors as presented in Mendez (2015). Qualities like hard work, responsibility, thrift and perseverance are expected to be tightly related to the conscientiousness factor. Obedience and good manners are also expected to be positively associated to conscientiousness. The same holds for obedience and agreeableness in its compliance facet. Religiosity in general and particularly so, open and mature religion, and spirituality are expected to be positively related to agreeableness and conscientiousness.

Imagination and tolerance are found to be positively associated to the openness to experience factor as described in Mendez (2015), while unselfishness and good manners are positively related to the agreeableness factor. Independent children are a priori less likely to act in a cooperative manner (A) or to be oriented toward the outer world of people and things (E). Finally, tolerance is expected to be related to almost all the personality factors.

The civic capital concept introduced in Guiso, Sapienza and Zingales (2010) is expected to be related to the Agreeableness personality factor, defined by the American Psychology Association Dictionary as "the tendency to act in a cooperative, unselfish manner". It is also reasonable to assume a positive association between civic capital and conscientiousness since the latter factor is defined as "the tendency to be organized, responsible and hardworking". It is the responsibility dimension of the conscientiousness factor what could produce a positive relationship with the civic capital concept introduced in Guiso, Sapienza and Zingales (2010). 
Tables 2, 3 and 4 provide a summarized description of the data at hand for each country of ancestry. In particular, in Table 2 we report the average value of the outcome variables used in our analysis. On the other hand, in Table 3 we summarize our cultural proxies by reporting the share of citizens, from each country of ancestry, that select each of the eleven child qualities as one of the top five that children should be encouraged to learn at home. Finally, in Table 4, we present the average score on the 1 to 10 scale of the four variables used to obtain the synthetic measure of civic capital, higher values reflect a higher agreement with the statement that a given behavior is justifiable. Mexicans, Italians, Indians and Chinese are the largest ethnic groups in our dataset. As Table 2 shows, the average completed years of education is highest for those respondents whose father was born in India, followed by Belgium, China and Korea. On the other hand, the average number of years of education is lowest for those second-generation migrants from a Portuguese ancestry, followed by Sweden and Spain. Those respondents with a Mexican ancestry are in lowest proportion in a high skilled occupation and receive the lowest average wages among all countries of ancestry represented in our dataset.

Looking at Table 3 we observe that Russia followed by Poland, Niger, Romania, and India are the cultures that value most hard work, as a quality children should learn at home. In the opposite side of the spectrum are the Northern European countries, Sweden and Norway. Other child qualities also related with the conscientiousness personality factor, like responsibility, are valued most in Austria, Chile and Germany, while thrift is valued most in Russia, China and Austria. Perseverance is valued most in Germany, China, Japan, Romania and Russia while obedience is valued most in Niger, India and Chile. Politeness is also valued most in Niger, followed by India and Romania and independence is valued most in China, Germany and Norway. Imagination is valued most in Spain, Mexico and Sweden. Religiosity is valued most in Poland, Chile and Ireland and unselfishness is valued most in the UK, Australia, Denmark and Ireland. Finally, concerning civic capital measures, presented in Table 4, we observe that Mexico is the country that presents highest rates of approval for most non-cooperative behaviors, followed by Chile. 


\section{Estimates}

This section presents our estimates for the effect of the intergenerational transmission of noncognitive skills on adult outcomes. We first comment on the estimation of the synthetic cultural variables and then we analyze the estimates of the effects of interest and some relevant robustness checks.

\subsection{The Cultural Variables}

Responses about the relevance of the eleven child qualities in the WVS are correlated across respondents and ancestries. This, in turn, means that the effect of the intergenerational transmission of a particular child quality, independently of the evaluation of all other child qualities, on adult outcomes cannot be identified, since simultaneously controlling for the evaluation of the eleven child qualities in the respondent's country of ancestry in our estimates leads to collinearity issues. Thus, we employed a principal component analysis on individual responses about the relevance of the eleven child qualities, using polychoric correlation, to take into account the discrete nature of the data. The first principal component captures the largest variation in the common underlying determinants to the social norms determining the valuation of child qualities across respondents. Once aggregated at the country-of-ancestry level, the first principal component proxies for variable $\widetilde{Z}_{1 j}$ in (1).

To further learn about the effect of the transmission of particular child qualities on adult outcomes, we extracted a total of three principal components denoted by $\widetilde{Z}_{11 j}$, $\widetilde{Z}_{12 j}$ and $\widetilde{Z}_{13 j}$, respectively, all of which presented eigenvalues greater than one. These principal components correlated differently with the different child qualities and, thus, the comparison of the coefficients associated to the three principal components in the estimation of equation (1) informs on the effect of different combinations of intergenerationally transmitted child qualities on adult outcomes.

As previously explained, the synthetic civic capital variable $\widetilde{Z}_{2 j}$ is obtained as the first principal component of the variation across ancestries of the responses to the four questions of the WVS that allow us to infer how much people value public goods. 
Table 5 attests that the evaluations of the child qualities in the WVS are correlated across respondents. For example, those respondents that selected perseverance as one of the five qualities that children should be encouraged to learn at home were also more likely to select independence, responsibility and imagination and less likely to select good manners, religious faith and obedience, than those that did not select perseverance. Also, those respondents that chose thrift were more likely to choose hard work and less likely to choose independence, imagination, tolerance and unselfishness.

Tables 6 and 7 resume the results of the principal component analysis for child qualities and civic capital measures, respectively. The first principal component extracted from the child quality evaluations accounts for approximately one fifth of the variation in the evaluation of child qualities across respondents, with the second and third components accounting for approximately $12 \%$ and $10 \%$ of that variation, respectively. Also in these tables we present correlations of the extracted principal components with child quality evaluations and civic capital measures, respectively, aggregated at the country of ancestry level. ${ }^{6}$ Looking at these estimated factor loadings and correlations we observe that the first principal component is positively correlated with independence, imagination, perseverance and responsibility and negatively related to obedience, religious faith and good manners. The second component correlates positively with hard work, thrift, and perseverance at the country of ancestry level, and negatively with obedience. Finally, the third principal component is positively related to responsibility, tolerance and perseverance at the country of ancestry level.

Regarding civic capital, as it is shown in Table 6, we observe that all the individual measures are highly correlated with the first principal component, at the country of ancestry level. The same result was observed in Guiso, Sapienza and Zingales (2010). The first principal component accounts for approximately half of the variation in responses to the four questions considered for the civic capital measure.

\footnotetext{
${ }^{6}$ Similar results were obtained on correlations at the individual level. Results available from the authors upon request.
} 


\subsection{Culture and Education}

Table 8 shows our estimates of the effect of the intergenerational transmission of noncognitive skills on educational attainment, measured as completed years of formal education. Estimates are obtained using the empirical specification presented in equation (1) and fathers' birthplace to assign cultural variables of a given country-of-ancestry to the second-generation immigrants in our sample. The first column resumes the estimates for the effects of interest obtained when we include the four synthetic cultural variables, obtained using principal components factor analysis, along with the following demographic controls: age, age squared, gender, per capita family income, number of own children in the family under 6, marital status, immigrant status of spouse if married, employment and education status of spouse if married, state, metropolitan area and year fixed effects. A bold number in Table 8 indicates that the coefficient associated to that cultural variable remains statistically significant at conventional significance levels when only that cultural variable is included in the estimation, as opposed to the four synthetic cultural variables simultaneously. ${ }^{7}$ This, in turn, informs on whether collinearity among the cultural variables drives our results or not. ${ }^{8}$

As previously argued, by comparing the estimated coefficients for the three cultural variables, extracted from the child qualities evaluations, we can learn on the effect of different combinations of intergenerationally transmitted qualities on adult outcomes. In particular, when simultaneously including $\widetilde{Z}_{11}, \widetilde{Z}_{12}$ and $\widetilde{Z}_{13}$ in the estimation the coefficient estimated for $\widetilde{Z}_{1 j}$ informs on the effect on the respondent's educational level of the inherited stock of those child qualities whose correlation with $\widetilde{Z}_{1 j}$ markedly differs according to Table 6 from their correlation with $\widetilde{Z}_{1 j^{\prime}}$ for $j^{\prime} \neq j$. This, in turn, means that our estimates are not informative about the effect of the transmission of the child qualities perseverance and unselfishness since they correlate almost identically with the three cultural variables.

By simultaneously controlling for the four cultural variables we find that the respon-

\footnotetext{
${ }^{7}$ These estimates are available upon request to the authors.

${ }^{8}$ Note that our factor analyses are performed at the respondent level and so, even though the extracted factors are independent at this level of analysis, the aggregated factors at the country of ancestry level are correlated with each other.
} 
dents with a higher educational level are those whose ancestries placed a higher value on child qualities such as thrift and particularly so on hardworking, and a lower value on imagination and tolerance, as qualities that children should be encouraged to learn at home. While hard work and thrift show the highest positive correlation with $\widetilde{Z}_{12}$, the principal component that exerts a positive effect on educational attainment, they are weakly or even negatively (hard work) associated to the other principal components. On the other hand, tolerance and imagination are negatively correlated with $\widetilde{Z}_{12}$, but they are positively associated to the other two cultural variables. In particular, tolerance shows the highest correlation with $\widetilde{Z}_{13}$. We also obtain some evidence suggesting that the effect of some child qualities might be non-linear on the inherited stock, with ancestries that place an average value on independence, responsibility, religious faith and obedience obtaining better educational outcomes. That is the case since the correlation between $\widetilde{Z}_{12}$ and the latter child qualities falls in between those with $\widetilde{Z}_{11}$ and $\widetilde{Z}_{13}$. Less clear-cut is the effect of the remaining child qualities.

The coefficient associated to the synthetic civic capital variable is positive and highly significant independently of whether we control for the principal components extracted from the chid quality variables or not ${ }^{9}$. This means that respondents from ancestries that placed a higher value on public goods report higher educational attainment on average than those who inherited a lower stock of civic capital. As the bold numbers in the table indicate, we reached the same results, regarding the relevance of the inherited stock of the child qualities hard work and thrift and also of civic capital, when only controlling for one cultural variable at a time.

A major concern with our results presented in the first column of Table 8 is that some omitted variable exists. As Fernandez and Fogli (2009) pointed out, unobserved differences in human capital, broadly defined, embodied either in the individual or in his ethnic network, is a major suspect. That is the case since human capital may well have an unobserved component that depends on the human capital of the respondent's parents, information that is not available to us as the March CPS only informs on

\footnotetext{
${ }^{9}$ Results without controlling for the cultural sythetic measures based on evaluations of child qualities are available from the authors upon request.
} 
parent's educational level for those co-residing. If parental education varies by ancestries in a way that is correlated with our cultural proxies, this could explain the estimates reported in Table 8.

To control for that possibility we use the 1970 U.S. census $1 \%$ sample that collects information on individuals' country of birth and educational level. ${ }^{10}$ In particular, we obtained summary measures of educational attainment for first generation men and women immigrants, from the respondents' country of ancestry, and aged 20 to 40 years old in 1970. This is the collective that most likely resembles the characteristic of the CPS respondents' parents at the time they arrived to the U.S. ${ }^{11}$ The resulting variables are aggregated ethnic human capital measures that are likely to affect current educational levels of CPS respondents not only because they approximate their parents' educational attainment, but because as Borjas $(1992,1995)$ showed, there might also be ethnic externalities in the human capital process.

Additionally, we also calculated the average number of children born alive to women at the end of their fertile period, from the respondent's country of ancestry, using the data from the 1970 census. We do so because the March CPS does not inform on the respondent's number of siblings and, as Chiswick (1988) showed, differences in schooling, across racial and ethnic groups in the U.S., are consistent with a child quality investment model in which group differences in fertility and female labor supply determine the price of quantity relative to quality of children. Thus, it might be the case that our estimates for the effect of interest in column (1) of Table 8 might be merely capturing differences in family size across ancestries, with family size determining which noncognitive skills are transmitted to children.

The estimates in column (2) are obtained using the same specification as in column (1) but adding the three variables obtained from the 1970 census as additional controls. We find a positive association between the years of formal education of first-generation immigrant women to the U.S. and the educational attainment of second-generation im-

\footnotetext{
${ }^{10}$ This information is not included in more recent census data sets.

${ }^{11}$ Alternatively, we also considered more general definitions that do not condition by age. The estimates of interest remain largely unchanged when using these alternative variables.
} 
migrants aged 25 to 35 years old from the same ancestry. The estimates of interest change their magnitude by at most $38 \%$ but they continue to be highly statistically significant and of the same sign as those in column (1). The exception is $\widetilde{Z}_{13}$, whose coefficient becomes not statistically significant once we control for aggregate ethnic human capital and fertility measures.

Finally, we also obtained separate estimates for men and women. Our results for these estimates, reported in columns (3) and (4) Table 8, respectively, suggest that the effect of the intergenerational transmission of child qualities on educational attainment is not different for second-generation men and women immigrants aged 25 to 35 years old in the U.S. However, the effect of the intergenerational transmission of civic capital is larger for men than it is for women. Also, the effect of the educational attainment of first-generation immigrant women is larger for women than it is for men, while we find a significant effect of average fertility in the country of ancestry for men. ${ }^{12}$

Our estimates support the hypothesis that the intergenerational transmission of both civic capital and of some child qualities positively related to the constientiousness personality factor, like hard work and thrift, favors educational attainment. These results are coherent with the finding in Cunha and Heckman (2008), Heckman, Pinto and Savelyev (2013) and Borghans, Meijers and Weel (2008), among others, that the conscientiousness personality factor plays a powerful role in explaining educational performance. Moreover, our estimates are also coherent with the finding in Mendez (2015) that the intergenerational transmission of child qualities positively associated to conscientiouness favors the acquisition of cognition as measured by PISA achievement tests. According to our preferred estimates from column (2) of Table 8, an increase of one standard deviation in $\widetilde{Z}_{12}$ accounts to $64.2 \%$ of the standard deviation in average educational attainment across ancestries. The corresponding number for $\widetilde{Z}_{2}$ is $35.6 \%$. It should be stressed however, as previously indicated, that our estimates are likely to provide a lower bound on the effect of interest since our identification strategy tends to underestimate the effect of culture (Fernandez and Fogli, 2009).

\footnotetext{
${ }^{12}$ These results are confirmed when using the whole estimation sample but adding interactions between gender and the cultural variables.
} 
In columns (1) and (2) of Table 9 we present estimates of marginal effects, using an ordered probit model, of the effect of interest for men and women, respectively, where the outcome variable is defined as the highest educational level obtained by the respondent, in three ordered categories: primary education or less, high school graduate and college degree or more. These estimates are qualitatively identical to those in Table 8 and they confirm the relevance of the inherited stock of both civic capital and of child qualities associated to conscientiousness in determining educational attainment.

Next, in columns (3) and (4), of Table 9, we focus on whether culture affects the probability of men and women successfully pursuing a college degree, conditional on having completed high school. Given the binary nature of our dependent variables, we estimated probit models and report probit marginal effects. We find that the transmission of child qualities positively associated to conscientiousness is more effective at increasing the probability of getting a college diploma, for those who have finished high school, than it is the transmission of civic capital. For men, our estimates imply that

a one standard deviation increase in $\widetilde{Z}_{12}$ and $\widetilde{Z}_{2}$ account for $26.8 \%$ and $12.7 \%$ of the standard deviation of the probability of holding a college diploma across countries, respectively. The corresponding numbers for women are $29.8 \%$ and $16.4 \%$, respectively. As before, our results remain qualitatively unchanged when we alternatively control for each of the four cultural variables one at a time.

\subsection{Culture and Labor outcomes}

In Table 10 we analyze the effect of the intergenerational transmission of noncognitive skills on adult employment outcomes, controlling for respondent's educational level. These estimates inform on the direct effect of culture on the respondents' probability of being employed, of working in one of the two major occupational groups (i.e. management, business, and financial occupations or professionals and related occupations), conditioning on working, and on the wage earned if employed, once the effect of culture on respondents' final level of education has been controlled for. Estimates for the effect of culture on wages also control for occupational status through a set of nine dummy 
variables for the respondent's type of occupation. In addition, as in previous sections, our estimates also control for the following demographic variables: age, age squared, gender, per capita family income, number of own children in the family under six, marital status, immigrant status of spouse if married, employment and education status of spouse if married, state, metropolitan area and year fixed effects.

The first three columns of Table 10 show the estimated marginal effects obtained from probit model regressions of the probability of being employed for the entire sample, as well as for men and women separately. These estimates suggest that neither inherited child qualities or the inherited stock of civic capital affect the probability of employment during adulthood. Only for women we find a positive association between inherit civic capital and a negative association for those ancestries that place a lower (higher) value on hard work (independence) on her probability of being employed at the time of the interview.

Columns (4) to (6) show marginal effects for the results of probit models on the probability of working on one of the two major occupational groups, while columns (7) to (9) present the estimated coefficients on linear regression models for wages earned for those working, once we control for occupational type. The estimates for $\widetilde{Z}_{11}$ suggests that, regarding child qualities, after controlling for educational attaintment, those respondent's whose country of ancestry placed a lower value on hard work and a higher value on independence, have a lower probability of being in a top occupation if employed, and, given occupational status, they also perceive lower wages if employed. The estimates for $\widetilde{Z}_{12}$ offer complementary but weak evidence that those respondents whose ancestry placed a higher value on hard work and thrift have a higher probability of working in one of the two major occupational groups. These results are robust to the correction of sample selection biases in women's estimates using Heckman (1978)'s approach. ${ }^{13}$ A one standard deviation increase in $\widetilde{Z}_{11}$ and $\widetilde{Z}_{12}$ would account for $65.9 \%$ and $121.0 \%$ of the standard deviation in the share of men and women employed in the two major occupations across ancestries, respectively. An equivalent increase in $\widetilde{Z}_{11}$ accounts for $23.8 \%$ to $12.1 \%$ of the standard deviation of average wages across ancestries.

\footnotetext{
${ }^{13}$ These estimates are available upon request to the authors.
} 
Finally, to further learn about the effect of culture on wages we estimated a quantile regression model which results, for both men and women together, are summarized in Table 11. These estimates attest that the stock of civic capital transmitted from parents to children does not affect the wage earned if employed, no matter the percentile of the wage distribution considered. On the other hand, the estimate for $\widetilde{Z}_{11}$ suggests that the lower the weight the respondent's cultural heritage places on hard work and the higher the weight on independence, the lower the probability that he/she earns a higher wage but only for wages above the median of the wage distribution. The latter effect is larger the higher is the percentile considered. Finally, our results of the intergenerational transmission of noncognitive skills on labor market outcomes go also in line with the results of Cawley, Heckman \& Vytlacil (2001) who found that, once educational attainment or cognitive ability is controlled for, personality traits still present a correlation with earnings but this correlation is weaker as noncognitive skills seem to operate mostly through schooling attainment.

\subsection{Robustness Checks}

We first analyze whether the effects of interest are heterogeneous in the mother's birthplace. The intuition behind this test is that if culture is driving our results the effect of interest should be reinforced if both parents were born in the same foreign country. Thus, we expanded the specifiation in (1) to allow for differential effects of our synthetic cultural variables depending on whether both parents are born in the same foreign country, whether both parents are migrants but from different foreign countries, and whether the father is migrant but the mother was born in the U.S. In our main estimation sample, in about $54 \%$ of the cases the respondent's parents were both migrants from the same country, in $37 \%$ of the cases the father was migrant but the mother was born in the U.S, and only in a small proportion of cases, $8 \%$, both parents were migrants but from different countries of ancestry. The resulting estimates, summarized in Table 12, show that the intergenerational transmission of child qualities and civic capital is much stronger if both parents are foreigners from the same country of ancestry than if the 
father is migrant but the mother was born in the U.S. We do not observe significantly different effects, in years of education, across cases where both parents are foreigners of the same country or of different countries. However, we find that the previously estimated significant effects of the intergenerational transmisison of child qualities on the probability of having a top occupation and on wages are driven only from cases where both migrant parents share the same country of ancestry. No effects are observed, in labor outcomes, for respondents with a foreign father but an American mother. Thus, we conclude that these estimates reinforce the validity of the cultural hypothesis.

Finally, we also checked whether our results were indeed driven by the largest ethnic group within the U.S., that is, by Mexicans. The results presented in Table 13 allow us to reject this hypothesis. These estimates confirm that the intergenerational transmission of child qualities positively associated to the conscientiousness personality factor improve educational attainment and, to a lesser extend, high occupational status. On the other hand, the transmission of cultures that give lower values to hard work and thrift, as preferred child qualities, present lower levels of education, lower probability of being in a top occupation, and lower wages. The stock of civic capital plays a significant role on educational attainment but no effect is found in labor market outcomes. We also obtained similar results when we dropped the group of respondents from Canadian ancenstry, who we believe could most resemble American natives.

\section{Conclusions}

This paper contributes to the literature on noncognitive skills by analyzing the existence of a cultural component on their formation process and by testing for its effects on education and employment outcomes in adulthood. We define culture as the set of beliefs and preferences that conditions individuals' actions, that systematically vary across either socially or geographically defined groups, and that are transmitted to successive generations.

To identify the effect of culture we use the so-called "epidemiological approach" (Fernandez, 2008) and we compare adult outcomes of second-generation immigrant groups 
facing the same markets and institutions, but differing in their cultural heritage. In particular, we use pooled 2005-2012 March Current Population Survey (CPS) data to obtain information on American second-generation immigrants' educational attainment and labor market outcomes. Additionally, we use the first two waves of the World Values Survey (WVS), carried out around 1981 and 1990, respectively, to approximate respondents' cultural heritage.

We consider two measures of noncognitive skills. On the one hand, we analyze country differences in the personality traits that children are encouraged to learn at home. On the other hand, we analyze the relevance of the noncognitive skills embodied in the concept of civic capital, introduced in Guiso, Sapienza and Zingales (2010) and defined as the set of beliefs and values that help cooperation in society.

Our estimates suggest that the intergenerational transmission of certain noncognitive skills plays a prominent role in determining individuals' final educational level. In particular, we find that individuals whose cultural heritage places a higher value on the child qualities positively asociated to the conscientiousness personality factor like hard work and thrift, as qualities to encourage in children, declare a higher educational level and, in particular, they are more likely to have a college degree. These findings are in line with the large body of evidence summarized in Almlund et al. (2011) showing that personality measures related to the conscientiousness personality factor, like hardworking, predict educational attainment and other adult outcomes. We also find that individuals with a higher inherited civic capital declare a higher educational level.

Concerning labor outcomes, similar to findings in Cawley, Heckman and Vytlacil (2001), we find that the effect of the intergenerational transmission of noncognitive skills have a smaller effect in these outcomes, once educational attaintment is controlled for. However, we still find a negative and statistically significant effect on the probability of being employed in one of the first two major occupational categories and on the wage earned if employed, even after accounting for occupational status, for those whose cultural heritage places a lower value on child qualities related to the conscientiousness personality factor. We do not find a significant effect of inherited civic capital on adult labor market outcomes. This, in turn, suggests that a certain level of both inherited 
civic capital and conscientiousness are relevant for educational success whereas only the inherited stock of conscientiousness matters for achieving success in the labor market.

According to our preferred estimates, the transmission of child qualities positively associated to conscientiousness like hard work and thirft and of civic capital account for $64 \%$ and $36 \%$ of the standard deviation of average education attainment across ancestries, respectively. Additionally, we find that a one standard deviation increase in the percentage of citizens from the respondent's country of ancestry that value those qualities, as a relevant for children to learn at home, accounts for at least $66 \%$ of the standard deviation of the share of high-skilled workers across ancestries. These estimates are likely to provide a lower bound on the effects of interest since our identification strategy tends to underestimate the effect of culture. This is so, because of the attenuation of cultural effects when living in a different country, as well as the possibility that those who migrated might be those who shared more cultural values with the U.S.

Finally, this paper also contributes to the literature by proposing an explanation for the observed differential performance and assimilation rates of second generation migrants from different countries of ancestry (see, e.g., Chiswick and DebBurman , 2004). From the point of view of public policy, this is important as policies oriented to improve the noncognitive skills of those groups with higher difficulty could be a promissing strategy for improving outcomes of those migrant groups that lag behind. 


\section{References}

[1] Alesina, Alberto, and Paola Giuliano. 2010. The power of the family. Journal of Economic Growth 15, no. 2: 93-125.

[2] Alesina, Alberto, Giuliano, Paola and Nathan Nunn. 2011. Fertility and the plough. American Economic Review: Papers \& Proceedings 101, no. 3: 499-503.

[3] Algan, Yann, and Pierre Cahuc. 2005. The roots of low European employment: Family culture?. In: NBER International Seminar on Macroeconomics 2005, NBER Chapters: 65-109.

[4] Algan, Yann, and Pierre Cahuc. 2006. Civic attitudes and the design of labor market institutions: Which countries can implement the Danish flexicurity model?. CEPR Discussion Papers no. 5489.

[5] Almlund, Mathilde, Duckworth, Angela L., Heckman, James J., and Tim D. Kautz. 2011. Personality psychology and economics. In Handbook of the Economics of Education, ed. Hanushek Erik A. and Stephen Machin, \& L. Wößmann (Eds.), Amsterdam, Elsevier.

[6] Arias, Beatriz M. 1986. The context of education for Hispanic students: An overview. American Journal of Education 95: 26-57.

[7] Borghans, Lex, Meijers, Huub, and Bas T. Weel. 2008. The role of noncognitive skills in explaining cognitive test scores. Economic Inquiry 46, no. 1: 2-12.

[8] Borjas, George J. 1992. Ethnic capital and intergenerational mobility. Quarterly Journal of Economics 107, no. 1: 123-150.

[9] Borjas, George J. 1995. Ethnicity, neighborhoods, and human-capital externalities.American Economic Review 85, no. 3: 365-90.

[10] Brunello, Giorgio, and Martin Schlotter. 2011. Non cognitive skills and personality traits: Labor market relevance and their development in education \& training systems. IZA Discussion Paper no.5743. 
[11] Cawley, John, Heckman, James J., and Edward J. Vytlacil. 2001. Three observations on wages and measured cognitive ability. Labour Economics 8, no. 4: 419-442.

[12] Chiswick, Barry R. 1988. Differences in education and earnings across racial and ethnic groups: Tastes, discrimination, and investments in child quality. The Quarterly Journal of Economics 103, no. 3: 571-597.

[13] Chiswick, Barry R., and Noyna DebBurman N. 2004. Educational attainment: analysis by immigrant generation. Economics of Education Review 23, no. 4: 361-379.

[14] Costa, Paul T., and Robert R. McCrae. 1992. Revised NEO Personality Inventory (NEOPI-R) and the NEO Five-Factor Inventory (NEO-FFI) professional manual. Psychological Assessment Resources. Odessa, Florida.

[15] Cunha, Flavio, and James J. Heckman. 2008. Formulating, identifying and estimating the technology of cognitive and noncognitive skill formation. Journal of Human Resources 43, no. 4: 738-782.

[16] Dohmen, Thomas, Falk, Armin, Huffman, David, and Uwe Sunde. 2012. The intergenerational transmission of risk and trust attitudes. Review of Economic Studies 79, no. 2: 645-677.

[17] Fernandez, Raquel. 2008. Culture and economics. In New Palgrave Dictionary of Economics 2nd edition, ed. Durlauf Steven N. and Lawrence E. Blume. New York. NY: Palrave and Macmillian.

[18] Fernandez, Raquel. 2011. Does culture matter?. In Handbook of Social Sciences,

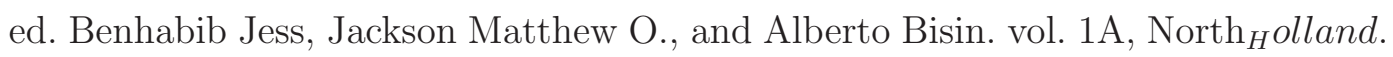

[19] Fernandez, Raquel, and Alessandra Fogli. 2009. Culture: An empirical investigation of beliefs, work, and fertility. American Economic Journal: Macroeconomics 1, no. 1: 146-177.

[20] Giuliano, Paola. 2007. Living arrangements in Western Europe: Does cultural origin matter?. Journal of the European Economic Association 5, no. 5: 927-952. 
[21] Gough, Harrison G. and Alfred B. Heilbrun. 1983. The adjective check list manual. Consulting Psychologists Press. Palo Alto, CA.

[22] Guiso, Luigi, Sapienza, Paola and Luigi Zingales. 2006. Does culture affect economic outcomes?. Journal of Economic Perspectives 20, no. 2: 23-48.

[23] Guiso, Luigi, Sapienza, Paola, and Luigi Zingales. 2009. Cultural biases in economic exchange?. The Quarterly Journal of Economics 124, no. 3: 1095-1131.

[24] Guiso, Luigi, Sapienza, Paola, and Luigi Zingales. 2010. Civic capital as the missing link. In Social Economics Handbook, ed. Benhabib Jess, Bisin Alberto and Matthew O. Jackson, no. 1. Elsevier.

[25] Hansen, Christian B. 2007. Asymptotic properties of a robust variance matrix estimator for panel data when $\mathrm{T}$ is large. Journal of Econometrics 141: 597-620.

[26] Heckman, James J. 2011. Integrating personality psychology into economics. IZA Discussion Paper no. 5950, Institute for the Study of Labor (IZA).

[27] Heckman, James J. and Tim Kautz. 2013. Fostering and measuring skills: Interventions that improve character and cognition. NBER WorkingPaper no. 19656. National Bureau of Economic Research.

[28] Heckman, James J., Rodrigo, Pinto, and Peter Savelyev. 2013. Understanding the mechanisms through which an influential early childhood program boosted adult outcomes. American Economic Review 103, no. 6: 2052-86.

[29] Hirschman, Charles, and Morrison G. Wong. 1986. The extraordinary educational attainment of Asian Americans: A search for historical evidence and explanations.Social Forces 65, no. 1: 1-27.

[30] Lee, Everett S., and Xue-Ian Rong. 1988. The educational and economic achievement of Asian Americans. Elementary School Journal 88, no. 5: 545-560. 
[31] Lindqvist, Erik, and Roine Vestman. 2011. The labor market returns to cognitive and noncognitive ability: Evidence from the Swedish enlistment. American Economic Journal: Applied Economics 3, no. 1: 101-128.

[32] Mendez, Ildefonso. 2015. The effect of the intergenerational transmission of noncognitive skills on student performance. Economics of Education Review 46 (June): 78-97.

[33] Roland, Gerard. 2004. Understanding institutional change: Fast-moving and slowmoving institutions. Studies in Comparative International Development 38, no. 4: 109131.

[34] Tabellini, Guido. 2010. Culture and institutions: Economic development in the regions of Europe. CESifo Working Paper Series no. 1492, CESifo Group, Munich.

[35] US Department of Education. 2013. Promoting grit, tenacy, and perseverance: Critical factors for sucess in the 21st Century.

[36] Velez, William. 1989. High school attrition among Hispanic and Non-Hispanic white youths. Sociology of Education 62, no. 2: 119-133.

[37] Weber, Max. 1905. The protestant ethic and the spirit of capitalism, ed. Unwin Hyman, London Boston, 1930. 
Table 1. The Big Five domains and their expected correlation with the child qualities

\begin{tabular}{|c|c|c|c|c|c|}
\hline $\begin{array}{l}\text { Big Five } \\
\text { factors }\end{array}$ & $\begin{array}{l}\text { American Psychology } \\
\text { Association Dictionary }\end{array}$ & $\begin{array}{c}\text { Facets (and correlated } \\
\text { trait adjective) }\end{array}$ & Related Traits & \begin{tabular}{|c|} 
Childhood \\
Temperament Traits
\end{tabular} & $\begin{array}{l}\text { Expected correlation } \\
\text { with child qualities }\end{array}$ \\
\hline Conscientiousness & $\begin{array}{l}\text { "the tendency to be } \\
\text { organized, responsible, } \\
\text { and hardworking" }\end{array}$ & $\begin{array}{c}\text { Competence (efficient) } \\
\text { Order (organized) } \\
\text { Dutifulness (not careless) } \\
\text { Achievement striving } \\
\text { (ambitious) } \\
\text { Self-discipline (not lazy) } \\
\text { Deliberation (not } \\
\text { impulsive) }\end{array}$ & $\begin{array}{c}\text { Grit } \\
\text { Perseverance } \\
\text { Delay of gratification } \\
\text { Impulse control } \\
\text { Achievement striving } \\
\text { Ambition } \\
\text { Work ethic }\end{array}$ & $\begin{array}{c}\text { Attention/(lack of) } \\
\text { distractibility } \\
\text { Effortful control } \\
\text { Impulse control/delay } \\
\text { of gratification } \\
\text { Persistence } \\
\text { Activity* }\end{array}$ & $\begin{array}{c}\text { Hard work } \\
\text { Responsability } \\
\text { Thrift } \\
\text { Perseverance } \\
\text { Religious faith (-) } \\
\text { Obedience }\end{array}$ \\
\hline $\begin{array}{l}\text { Openness to } \\
\text { Experience }\end{array}$ & $\begin{array}{l}\text { "the tendency to be open } \\
\text { to new aesthetic, } \\
\text { cultural, or intellectual } \\
\text { experiences" }\end{array}$ & $\begin{array}{c}\text { Fantasy (imaginative) } \\
\text { Aesthetic (artistic) } \\
\text { Feelings (excitable) } \\
\text { Actions (wide interests) } \\
\text { Ideas (curious) } \\
\text { Values (unconventional) }\end{array}$ & - & $\begin{array}{l}\text { Sensory sensitivity } \\
\text { Pleasure in low } \\
\text { intensity activities } \\
\text { Curiosity }\end{array}$ & $\begin{array}{l}\text { Imagination } \\
\text { Tolerance }\end{array}$ \\
\hline Extraversion & \begin{tabular}{|} 
"an orientation of one's \\
interests and energies \\
toward the outer world \\
of people and things \\
rather than the inner \\
world of subjective \\
experience; characterized \\
by positive affect and \\
sociability"
\end{tabular} & $\begin{array}{c}\text { Warmth (friendly) } \\
\text { Gregariousness (sociable) } \\
\text { Assertiveness (selfconfident) } \\
\text { Activity (energetic) } \\
\text { Excitement seeking } \\
\text { (adventurous) } \\
\text { Positive emotions } \\
\text { (enthusiastic) }\end{array}$ & - & \begin{tabular}{|c|} 
Surgency \\
Social dominance \\
Social vitality \\
Sensation seeking \\
Shyness* \\
Activity* \\
Positive emotionality \\
Sociability/affiliation
\end{tabular} & $\begin{array}{c}\text { Tolerance } \\
\text { Independence (-) }\end{array}$ \\
\hline Agreeableness & $\begin{array}{c}\text { "the tendency to act in a } \\
\text { cooperative, unselfish } \\
\text { manner" }\end{array}$ & $\begin{array}{c}\text { Trust (forgiving) } \\
\text { Straight-forwardness (not } \\
\text { demanding) } \\
\text { Altruism (warm) } \\
\text { Compliance (not stubborn) } \\
\text { Modesty (not show-off) } \\
\text { Tender-mindedness } \\
\text { (sympathetic) }\end{array}$ & $\begin{array}{c}\text { Empathy Perspective } \\
\text { taking Cooperation } \\
\text { Competitiveness }\end{array}$ & $\begin{array}{l}\text { Irritability* } \\
\text { Aggressiveness } \\
\text { Willfulness }\end{array}$ & $\begin{array}{c}\text { Good manners } \\
\text { Independence (-) } \\
\text { Tolerance } \\
\text { Religious faith (-) } \\
\text { Unselfishness } \\
\text { Obedience }\end{array}$ \\
\hline $\begin{array}{c}\text { Neuroticism/ } \\
\text { Emotional } \\
\text { Stability }\end{array}$ & $\begin{array}{l}\text { Emotional stability is } \\
\text { "predictability and } \\
\text { consistency in emotional } \\
\text { reactions, with absence } \\
\text { of rapid mood changes." } \\
\text { Neuroticism is "a chronic } \\
\text { level of emotional } \\
\text { instability and proneness } \\
\text { to psychological distress." }\end{array}$ & $\begin{array}{c}\text { Anxiety (worrying) } \\
\text { Hostility (irritable) } \\
\text { Depression (not contented) } \\
\text { Self-consciousness (shy) } \\
\text { Impulsiveness (moody) } \\
\text { Vulnerability to stress } \\
\text { (not self-confident) }\end{array}$ & \begin{tabular}{|} 
Internal vs. External \\
Locus of control \\
Core self-evaluation \\
Self-esteem \\
Self-efficacy \\
Optimism \\
Axis I \\
psychopathologies \\
(mental disorders) \\
including depression and \\
anxiety disorders
\end{tabular} & \begin{tabular}{|} 
Fearfulness/behavioral \\
inhibition \\
Shyness* \\
Irritability* \\
Frustration \\
(Lack of) soothability \\
Sadness
\end{tabular} & $\begin{array}{l}\text { Tolerance (-) } \\
\text { Obedience (-) }\end{array}$ \\
\hline
\end{tabular}

Notes: All the columns but the last one are taken from table 1 in Heckman (2011). Facets specified by the NEO-PI-R personality inventory (Costa and McCrae, 1992). Trait adjectives in parenthesis from the Adjective Check List (Gough and Heilbrun, 1983). * These temperament traits may be related to two Big Five factors. 
Table 2. Country summary statistics (I).

\begin{tabular}{|c|c|c|c|c|c|c|c|}
\hline $\begin{array}{c}\text { Country of } \\
\text { ancestry }\end{array}$ & $\begin{array}{c}\text { Sample } \\
\text { size }\end{array}$ & $\begin{array}{c}\begin{array}{c}\text { Education } \\
\text { (years) }\end{array}\end{array}$ & $\begin{array}{c}\text { High school } \\
\text { diploma }\end{array}$ & $\begin{array}{l}\text { College } \\
\text { diploma }\end{array}$ & Work & $\begin{array}{l}\text { Employed in } \\
\text { occup. } 1 \text { or } 2\end{array}$ & Log wage \\
\hline Argentina & 15 & 14.06 & 53.11 & 4.10 & 93.33 & 47.03 & 10.63 \\
\hline Australia & 15 & 14.86 & 7.14 & 73.33 & 93.33 & 60.21 & 10.85 \\
\hline Austria & 23 & 14.65 & 30.62 & 56.52 & 86.95 & 26.62 & 10.36 \\
\hline Belgium & 11 & 15.90 & 9.10 & 72.72 & 90.90 & 63.52 & 10.55 \\
\hline Canada & 371 & 14.10 & 23.52 & 50.94 & 78.97 & 36.10 & 10.36 \\
\hline Chile & 10 & 14.20 & 40.01 & 4.03 & 70.00 & 70.02 & 10.35 \\
\hline China & 393 & 15.56 & 6.52 & 80.40 & 81.17 & 58.81 & 10.59 \\
\hline Denmark & 16 & 14.56 & 25.63 & 56.25 & 93.75 & 69.60 & 10.81 \\
\hline France & 50 & 14.52 & 26.21 & 54.01 & 78.00 & 48.71 & 10.46 \\
\hline Germany & 377 & 14.48 & 19.01 & 56.76 & 82.75 & 41.07 & 10.46 \\
\hline Hungary & 53 & 14.73 & 23.00 & 60.37 & 71.69 & 39.31 & 10.43 \\
\hline India & 409 & 16.48 & 5.03 & 88.01 & 78.72 & 64.32 & 10.90 \\
\hline Ireland & 80 & 15.01 & 18.08 & 61.25 & 81.25 & 36.81 & 10.56 \\
\hline Italy & 451 & 14.40 & 23.20 & 53.88 & 81.15 & 43.11 & 10.51 \\
\hline Japan & 134 & 14.40 & 20.89 & 54.47 & 69.40 & 31.10 & 10.31 \\
\hline Korea & 229 & 15.33 & 10.48 & 73.36 & 77.29 & 46.91 & 10.59 \\
\hline Mexico & 1172 & 12.69 & 33.53 & 24.57 & 77.73 & 21.12 & 10.12 \\
\hline Netherlands & 69 & 15.44 & 13.04 & 65.21 & 81.15 & 46.61 & 10.45 \\
\hline Niger & 75 & 15.26 & 10.66 & 70.66 & 78.66 & 59.51 & 10.56 \\
\hline Norway & 27 & 14.92 & 7.40 & 74.07 & 66.76 & 56.55 & 10.14 \\
\hline Poland & 121 & 15.30 & 11.57 & 72.72 & 80.99 & 50.82 & 10.54 \\
\hline Portugal & 234 & 13.92 & 28.63 & 45.72 & 80.76 & 35.00 & 10.43 \\
\hline Romania & 17 & 14.82 & 17.64 & 58.82 & 94.11 & 41.01 & 10.48 \\
\hline Russia & 11 & 14.54 & 36.36 & 63.63 & 63.63 & 55.07 & 10.20 \\
\hline Spain & 54 & 14.01 & 29.62 & 44.44 & 92.59 & 37.03 & 10.56 \\
\hline Sweden & 13 & 14.00 & 23.07 & 30.76 & 84.61 & 62.61 & 10.62 \\
\hline United Kingdom & 256 & 14.60 & 21.09 & 56.25 & 77.73 & 45.54 & 10.45 \\
\hline
\end{tabular}

Notes: We report population-weighted averages. 


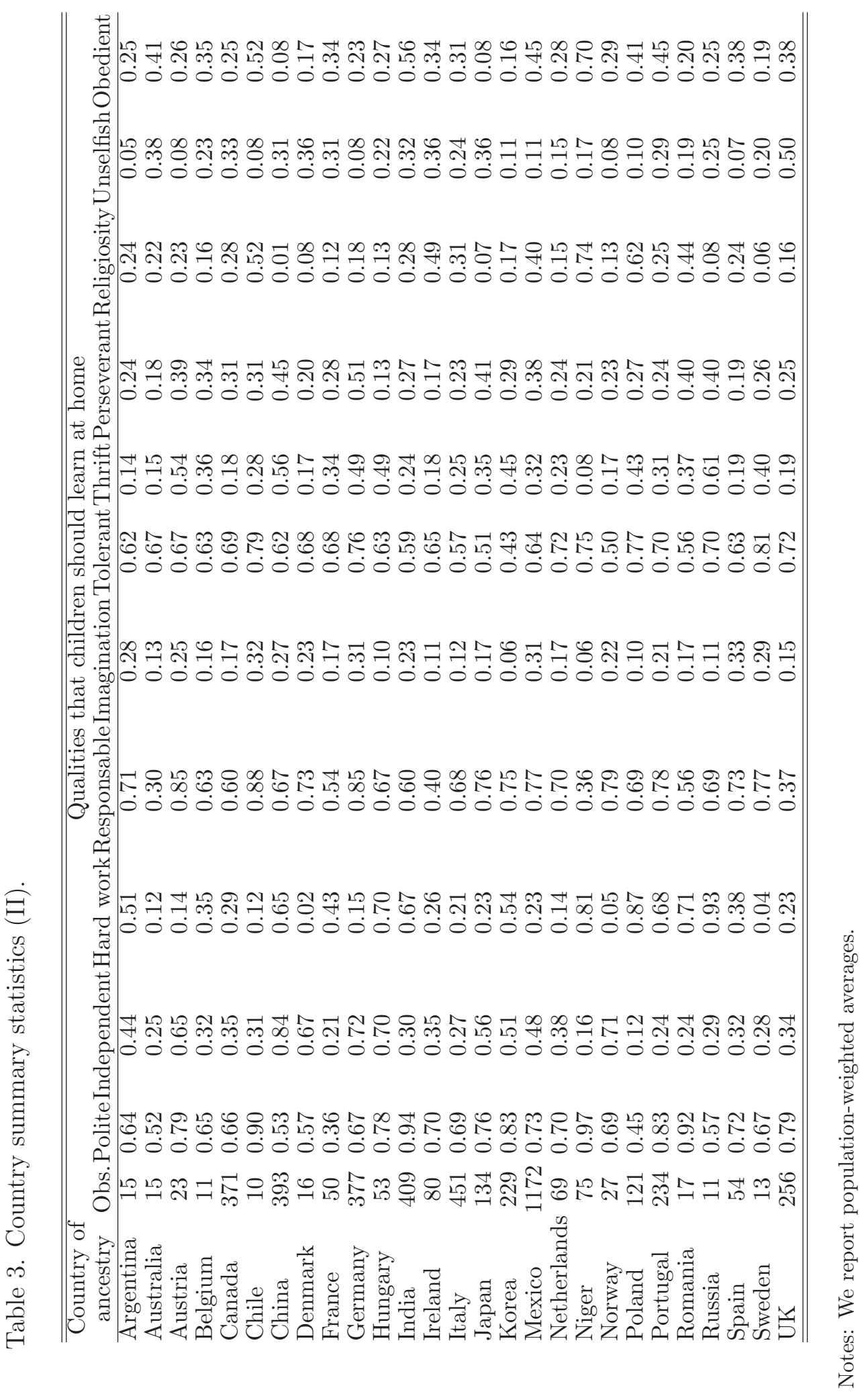


Table 4. Country summary statistics (III)

\begin{tabular}{lccccc}
\hline \hline Country of Ancestry & Obs. & Claim Benefit & Avoid Fare & Cheating Taxes & Accept Bribe \\
\hline Argentina & 15 & 2.05 & 2.17 & 1.90 & 0.82 \\
Australia & 15 & 1.85 & 2.43 & 3.10 & 1.72 \\
Austria & 23 & 1.70 & 1.93 & 2.01 & 1.63 \\
Belgium & 11 & 2.46 & 2.33 & 3.84 & 2.32 \\
Canada & 371 & 2.09 & 2.19 & 2.31 & 1.62 \\
Chile & 10 & 4.05 & 3.15 & 1.85 & 1.45 \\
China & 393 & 1.61 & 1.43 & 1.46 & 1.10 \\
Denmark & 16 & 1.24 & 1.69 & 2.39 & 0.86 \\
France & 50 & 3.37 & 2.54 & 3.16 & 2.31 \\
Germany & 377 & 2.04 & 2.19 & 2.72 & 1.91 \\
Hungary & 53 & 2.81 & 3.28 & 3.11 & 2.73 \\
India & 409 & 1.77 & 1.46 & 1.50 & 1.40 \\
Ireland & 80 & 1.87 & 2.33 & 3.01 & 1.41 \\
Italy & 451 & 1.79 & 1.84 & 2.22 & 1.76 \\
Japan & 134 & 1.92 & 1.52 & 1.46 & 1.81 \\
S. Korea & 229 & 2.17 & 2.47 & 1.54 & 1.92 \\
Mexico & 1172 & 4.91 & 4.15 & 3.80 & 2.75 \\
Netherlands & 69 & 1.51 & 2.32 & 3.05 & 1.89 \\
Niger & 75 & 2.04 & 2.41 & 2.22 & 2.07 \\
Norway & 27 & 1.43 & 1.63 & 3.20 & 1.40 \\
Poland & 121 & 2.12 & 1.85 & 2.64 & 1.58 \\
Portugal & 234 & 2.64 & 2.81 & 3.72 & 1.65 \\
Romania & 17 & 1.71 & 2.29 & 2.02 & 2.05 \\
Russia & 11 & 2.11 & 2.72 & 2.88 & 1.46 \\
Spain & 54 & 2.45 & 2.31 & 2.62 & 1.49 \\
Sweden & 13 & 1.53 & 1.81 & 2.15 & 1.61 \\
UK & 256 & 1.74 & 2.03 & 2.59 & 1.56 \\
\hline \hline
\end{tabular}

Notes: We report population-weighted averages 


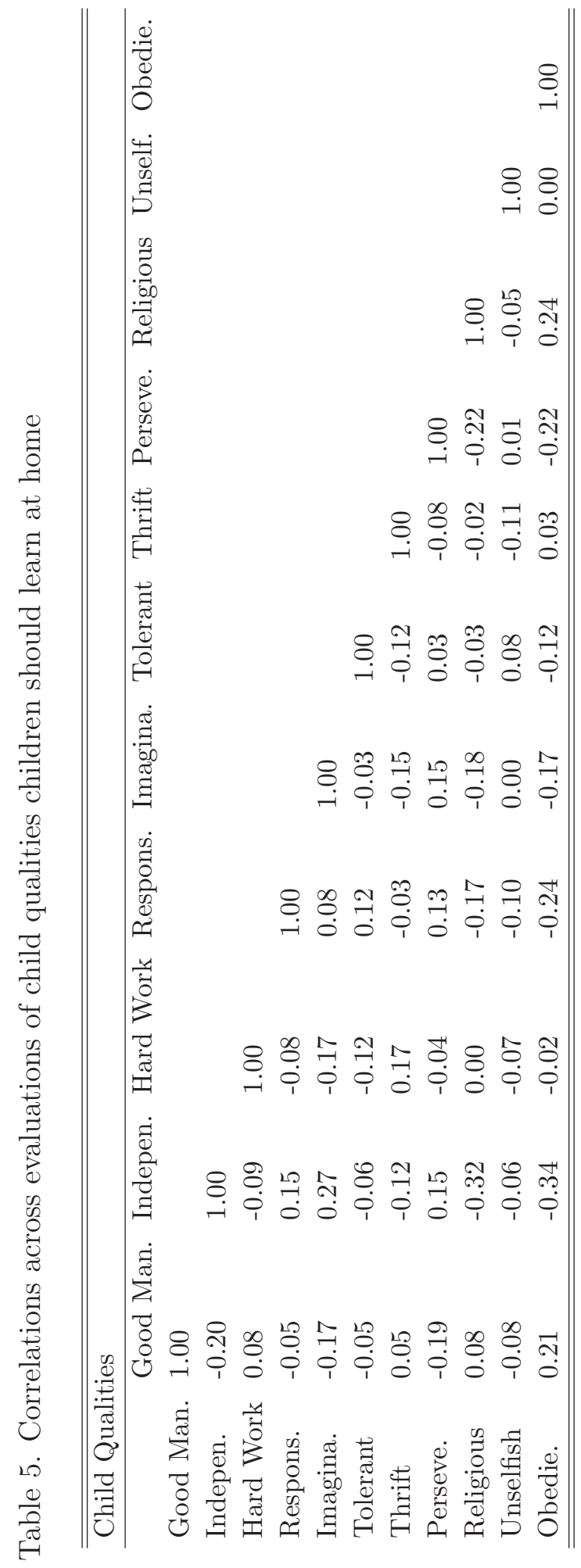


Table 6. Factor analysis results in the determination of the synthetic cultural measures and correlations, at the country of ancestry level, with evaluations of child qualities children should learn at home $\left(\widetilde{Z}_{11}, \widetilde{Z}_{12}, \widetilde{Z}_{13}\right)$

\begin{tabular}{lccc}
\hline \hline & \multicolumn{3}{c}{ Components } \\
\hline & First & Second & Third \\
Eigenvalue & 2.22 & 1.33 & 1.12 \\
\% Variance explained & 20.20 & 12.12 & 10.22 \\
N. Obs=85,589 & & & \\
Factor Loadings & & & \\
Good Manners & $\mathbf{- 0 . 3 4}$ & 0.09 & 0.04 \\
Independence & $\mathbf{0 . 5 5}$ & 0.10 & -0.17 \\
Hard Work & -0.17 & $\mathbf{0 . 3 5}$ & 0.03 \\
Responsible & $\mathbf{0 . 3 2}$ & 0.08 & 0.22 \\
Imagination & $\mathbf{0 . 4 1}$ & -0.12 & -0.20 \\
Tolerance & 0.10 & -0.22 & $\mathbf{0 . 3 1}$ \\
Thrift & -0.18 & $\mathbf{0 . 3 4}$ & 0.03 \\
Perseverance & $\mathbf{0 . 3 8}$ & 0.02 & 0.05 \\
Religious Faith & $\mathbf{- 0 . 4 4}$ & -0.16 & -0.02 \\
Unselfish & 0.02 & -0.24 & 0.02 \\
Obedient & $\mathbf{- 0 . 5 2}$ & -0.13 & -0.14 \\
\hline Country-Level Correlations & & & \\
Good Manners & -0.46 & -0.14 & 0.22 \\
Independence & $\mathbf{0 . 8 1}$ & 0.41 & -0.14 \\
Hard Work & -0.25 & $\mathbf{0 . 7 5}$ & 0.23 \\
Responsible & $\mathbf{0 . 6 2}$ & 0.46 & $\mathbf{0 . 6 4}$ \\
Imagination & 0.44 & -0.23 & 0.12 \\
Tolerance & 0.01 & -0.25 & $\mathbf{0 . 6 7}$ \\
Thrift & 0.36 & $\mathbf{0 . 7 3}$ & $\mathbf{0 . 5 0}$ \\
Perseverance & $\mathbf{0 . 5 3}$ & $\mathbf{0 . 5 6}$ & $\mathbf{0 . 5 3}$ \\
Religious Faith & $\mathbf{- 0 . 7 9}$ & -0.40 & -0.13 \\
Unselfish & -0.14 & -0.23 & -0.17 \\
Obedient & $\mathbf{- 0 . 7 8}$ & $\mathbf{- 0 . 5 2}$ & -0.14 \\
\hline \hline & & & \\
\hline \hline & & & \\
& & &
\end{tabular}


Table 7. Factor analysis results for civic capital measures and correlations, at the country of ancestry level, with responses to individual questions $\left(\widetilde{Z}_{2}\right)$

\begin{tabular}{lccccc}
\hline \hline & First comp. & Claim Benefits & Avoid Fare & Cheat Taxes & Accept Bribe \\
\hline Claim Benefits & 0.84 & 1.00 & & & \\
Avoid Fare & 0.89 & 0.70 & 1.00 & & \\
Cheat Taxes & 0.73 & 0.43 & 0.53 & 1.00 & \\
Accept Bribe & 0.70 & 0.41 & 0.60 & 0.38 & 1.00 \\
\hline Eigenvalue & 2.03 & & & & \\
\hline \% Variance & 50.69 & & & & \\
\hline \hline
\end{tabular}


Table 8. Culture, noncognitive skills and educational attainment (years of education)

\begin{tabular}{|c|c|c|c|c|}
\hline & (1) & $(2)$ & $(3)$ & (4) \\
\hline$\widetilde{Z}_{11}$, child qualities & $\begin{array}{c}-0.219^{* * *} \\
(0.080)\end{array}$ & $\begin{array}{c}-0.306^{* * *} \\
(0.051)\end{array}$ & $\begin{array}{c}-0.298^{* * *} \\
(0.053)\end{array}$ & $\begin{array}{c}-0.313^{* * *} \\
(0.069)\end{array}$ \\
\hline$\widetilde{Z}_{12}$, child qualities & $\begin{array}{c}0.300 * * * \\
(0.062)\end{array}$ & $\begin{array}{c}0.418^{* * *} \\
(0.093)\end{array}$ & $\begin{array}{c}0.430 * * * \\
(0.118)\end{array}$ & $\begin{array}{c}0.402^{* * *} \\
(0.111)\end{array}$ \\
\hline$\widetilde{Z}_{13}$, child qualities & $\begin{array}{c}-0.144^{* *} \\
(0.064)\end{array}$ & $\begin{array}{l}-0.055 \\
(0.052)\end{array}$ & $\begin{array}{l}-0.047 \\
(0.051)\end{array}$ & $\begin{array}{l}-0.060 \\
(0.066)\end{array}$ \\
\hline$\widetilde{Z}_{2}$, civic capital & $\begin{array}{c}0.678^{* * *} \\
(0.057)\end{array}$ & $\begin{array}{c}0.445^{* * *} \\
(0.113)\end{array}$ & $\begin{array}{c}0.488^{* * *} \\
(0.104)\end{array}$ & $\begin{array}{c}0.395 * * * \\
(0.142)\end{array}$ \\
\hline Ethnic $\mathrm{n}$. of children & & $\begin{array}{c}0.375 \\
(0.231)\end{array}$ & $\begin{array}{c}0.541^{* *} \\
(0.224)\end{array}$ & $\begin{array}{c}0.250 \\
(0.253)\end{array}$ \\
\hline Ethnic Human Capital-Men & & $\begin{array}{l}-0.110 \\
(0.109)\end{array}$ & $\begin{array}{l}-0.044 \\
(0.121)\end{array}$ & $\begin{array}{l}-0.154 \\
(0.126)\end{array}$ \\
\hline Ethnic Human Capital-Women & & $\begin{array}{c}0.350 * * \\
(0.141)\end{array}$ & $\begin{array}{c}0.309 * * \\
(0.152)\end{array}$ & $\begin{array}{c}0.381^{* *} \\
(0.173)\end{array}$ \\
\hline Constant & $\begin{array}{c}6.005^{* *} \\
(2.652)\end{array}$ & $\begin{array}{c}2.411 \\
(2.896)\end{array}$ & $\begin{array}{c}2.894 \\
(4.855)\end{array}$ & $\begin{array}{c}3.536 \\
(4.143)\end{array}$ \\
\hline$R^{2}$ & 0.338 & 0.366 & 0.380 & 0.384 \\
\hline N. obs & 4686 & 4160 & 1989 & 2171 \\
\hline
\end{tabular}

Notes: The symbols $*{ }^{* *}$ and ${ }^{* * *}$ denote significance at the $10 \%, 5 \%$ and $1 \%$ significance level, respectively. The numbers in bold indicate that the coefficient associated to a cultural variable is statistically significant when not simultaneously controlling for the four cultural variables in the estimates but only for that cultural variable. The estimates include the following additional controls: Age, Age squared, gender, per capita family income, number of own children in the family under 6 , self-reported health, marital status, immigrant status of spouse, employment and education status of spouse, 50 state indicators, 3 metro indicators (urban, rural, metro) and year effects. Family income is converted into constant-1995 dollars prior to polling across years. 
Table 9. Culture, noncognitive skills and educational attaintment (educational levels), marginal effects estimates.

\begin{tabular}{|c|c|c|c|c|}
\hline & (1) & $(2)$ & $(3)$ & (4) \\
\hline$\widetilde{Z}_{11}$, child qualities & $\begin{array}{c}-0.127^{* * *} * \\
(0.047)\end{array}$ & $\begin{array}{c}-0.192^{* * *} \\
(0.046)\end{array}$ & $\begin{array}{c}-0.142^{* * *} \\
(0.051)\end{array}$ & $\begin{array}{c}-0.231^{* * *} \\
(0.058)\end{array}$ \\
\hline$\widetilde{Z}_{12}$, child qualities & $\begin{array}{c}0.241 * * * \\
(0.084)\end{array}$ & $\begin{array}{c}0.262^{* * *} \\
(0.067)\end{array}$ & $\begin{array}{c}0.326^{* * *} \\
(0.088)\end{array}$ & $\begin{array}{c}0.375 * * * \\
(0.079)\end{array}$ \\
\hline$\widetilde{Z}_{13}$, child qualities & $\begin{array}{l}-0.051^{*} \\
(0.026)\end{array}$ & $\begin{array}{c}-0.067^{* *} \\
(0.028)\end{array}$ & $\begin{array}{c}-0.080^{* *} \\
(0.038)\end{array}$ & $\begin{array}{c}-0.074^{* *} \\
(0.037)\end{array}$ \\
\hline$\widetilde{Z}_{2}$, civic capital & $\begin{array}{c}0.271^{* * *} \\
(0.060)\end{array}$ & $\begin{array}{c}0.246^{* * *} \\
(0.086)\end{array}$ & $\begin{array}{c}0.157 * * \\
(0.069)\end{array}$ & $\begin{array}{c}0.207 * * \\
(0.098)\end{array}$ \\
\hline Ethnic n. of children & $\begin{array}{c}0.159 \\
(0.100)\end{array}$ & $\begin{array}{c}0.230^{* *} \\
(0.111)\end{array}$ & $\begin{array}{c}0.180 \\
(0.120)\end{array}$ & $\begin{array}{c}0.428^{* * *} \\
(0.132)\end{array}$ \\
\hline Ethnic Human Capital-Men & $\begin{array}{l}-0.013 \\
(0.085)\end{array}$ & $\begin{array}{l}-0.084 \\
(0.066)\end{array}$ & $\begin{array}{l}-0.121 \\
(0.084)\end{array}$ & $\begin{array}{c}-0.185^{* *} \\
(0.083)\end{array}$ \\
\hline Ethnic Human Capital-Women & $\begin{array}{c}0.096 \\
(0.117)\end{array}$ & $\begin{array}{c}0.219 * * \\
(0.102)\end{array}$ & $\begin{array}{c}0.259^{* *} \\
(0.118)\end{array}$ & $\begin{array}{c}0.390^{* * *} \\
(0.126)\end{array}$ \\
\hline threshold1/Constant & $\begin{array}{c}4.226^{* *} \\
(2.131)\end{array}$ & $\begin{array}{c}3.364 \\
(2.879)\end{array}$ & $\begin{array}{l}-5.693^{*} \\
(2.982)\end{array}$ & $\begin{array}{l}-5.297 \\
(4.261)\end{array}$ \\
\hline threshold2 & $\begin{array}{c}6.069^{* * *} \\
(2.176)\end{array}$ & $\begin{array}{l}5.015^{*} \\
(2.872)\end{array}$ & & \\
\hline Pseudo $R^{2}$ & 0.206 & 0.225 & 0.234 & 0.300 \\
\hline N.obs & 1989 & 2171 & 1822 & 1914 \\
\hline
\end{tabular}

Notes: The symbols *, ${ }^{* *}$ and $* * *$ denote significance at the $10 \%, 5 \%$ and $1 \%$ significance level, respectively. The numbers in bold indicate that the coefficient associated to a cultural variable is statistically significant when not simultaneously controlling for the four cultural variables in the estimates but only for that cultural variable. The estimates include the following additional controls: Age, Age squared, gender, per capita family income, number of own children in the family under 6 , self-reported health, marital status, immigrant status of spouse, employment and education status of spouse, 50 state indicators, 3 metro indicators (urban, rural, metro) and year effects. Family income is converted into constant-1995 dollars prior to polling across years. 
Table 10. Culture, noncognitive skills and adult labor market outcomes.

\begin{tabular}{|c|c|c|c|c|c|c|c|c|c|}
\hline \multirow{3}{*}{ Child qualities } & \multicolumn{3}{|c|}{ Work } & \multicolumn{3}{|c|}{ Occupation } & \multicolumn{3}{|c|}{ Log. Wage } \\
\hline & All & Men & Women & All & Men & Women & All & Men & Women \\
\hline & & & & & & & & & \\
\hline \multirow[t]{2}{*}{$\widetilde{Z_{11}}$} & -0.003 & $0.080^{*}$ & $-0.093^{* *}$ & $-0.102 * * *$ & -0.074 & $-0.125 * *$ & $-0.037 * * *$ & $-0.051^{* *}$ & $-0.038^{*}$ \\
\hline & $(0.029)$ & $(0.044)$ & $(0.040)$ & $(0.033)$ & $(0.065)$ & $(0.050)$ & $(0.012)$ & $(0.019)$ & $(0.021)$ \\
\hline \multirow{2}{*}{$\widetilde{Z}_{12}$} & -0.023 & -0.000 & -0.022 & $0.135^{* *}$ & $0.219^{*}$ & 0.038 & 0.013 & -0.003 & 0.054 \\
\hline & $(0.063)$ & $(0.084)$ & $(0.074)$ & $(0.060)$ & $(0.123)$ & $(0.089)$ & $(0.019)$ & $(0.030)$ & $(0.044)$ \\
\hline \multirow[t]{2}{*}{$\widetilde{Z}_{13}$} & 0.000 & -0.016 & -0.005 & -0.023 & -0.004 & -0.046 & 0.007 & 0.005 & 0.003 \\
\hline & $(0.020)$ & $(0.040)$ & $(0.029)$ & $(0.031)$ & $(0.051)$ & $(0.031)$ & $(0.008)$ & $(0.017)$ & $(0.014)$ \\
\hline \multirow[t]{2}{*}{$\widetilde{Z}_{2}$, civic cap. } & 0.062 & $-0.136^{*}$ & $0.170^{* *}$ & 0.083 & 0.076 & 0.062 & -0.0005 & 0.003 & -0.066 \\
\hline & $(0.051)$ & $(0.081)$ & $(0.067)$ & $(0.071)$ & $(0.120)$ & $(0.086)$ & $(0.021)$ & $(0.032)$ & $(0.035)$ \\
\hline \multicolumn{10}{|c|}{ Ethnic vbles } \\
\hline \multirow[t]{2}{*}{ N. of children } & -0.092 & -0.193 & -0.094 & 0.138 & 0.159 & 0.104 & $0.096^{* * *}$ & 0.073 & $0.142^{* *}$ \\
\hline & $(0.091)$ & $(0.144)$ & $(0.139)$ & $(0.111)$ & $(0.182)$ & $(0.140)$ & $(0.031)$ & $(0.061)$ & $(0.065)$ \\
\hline \multirow[t]{2}{*}{ H. C.-Men } & 0.014 & 0.005 & 0.011 & $-0.138^{* *}$ & $-0.231^{*}$ & -0.035 & 0.016 & -0.000 & 0.020 \\
\hline & $(0.055)$ & $(0.072)$ & $(0.066)$ & $(0.059)$ & $(0.122)$ & $(0.083)$ & $(0.016)$ & $(0.033)$ & $(0.050)$ \\
\hline \multirow[t]{2}{*}{ H. C.-Women } & -0.059 & -0.050 & -0.060 & $0.241^{* * *}$ & 0.362 & 0.118 & 0.034 & 0.042 & 0.048 \\
\hline & $(0.077)$ & $(0.105)$ & $(0.090)$ & $(0.085)$ & $(0.166)$ & $(0.134)$ & $(0.024)$ & $(0.040)$ & $(0.070)$ \\
\hline \multirow[t]{2}{*}{ Constant } & -0.706 & -1.611 & 1.029 & -2.923 & 0.474 & $-5.675^{*}$ & 0.072 & -0.653 & 1.767 \\
\hline & $(2.995)$ & $(4.987)$ & $(3.582)$ & $(2.039)$ & $(2.740)$ & $(3.133)$ & $(1.639)$ & $(2.010)$ & $(2.163)$ \\
\hline (Pseudo) $\mathrm{R}^{2}$ & 0.129 & 0.145 & 0.173 & 0.240 & 0.262 & 0.252 & 0.222 & 0.233 & 0.242 \\
\hline N.obs & 4160 & 1989 & 2171 & 3293 & 1679 & 1614 & 2995 & 1530 & 1465 \\
\hline
\end{tabular}

Notes: The symbols $*{ }^{* *}$ and ${ }^{* * *}$ denote significance at the $10 \%, 5 \%$ and $1 \%$ significance level, respectively. The numbers in bold indicate that the coefficient associated to a cultural variable is statistically significant when not simultaneously controlling for the four cultural variables in the estimates but only for that cultural variable. I) The outcome variables in the work and occupation equations are dummies indicating whether the respondent works and whether, conditioned on working, his occupational status correspondes to the first two major occupational categories, respectively. The outcome variable in the wage equations is the log of respondets' wage and salary earnings. Thus, the table reports probit marginal effects for the employment and occupation equations and OLS estimates for the wage equation. II) The estimates include the following additional controls: Respondent's final education, age, Age squared, gender, per capita family income, number of own children in the family under 6 , self-reported health, marital status, immigrant status of spouse, employment and education status of spouse, 50 state indicators, 3 metro indicators (urban, rural, metro) and year effects. Family income is converted into constant-1995 dollars prior to polling across years. In addition, estimates in the last three columns also control for respondent's occupation. 
Table 11. Culture, noncognitive skills and adult log-annual wages (Quantile

Regressions)

\begin{tabular}{lccccccccc}
\hline \hline & $\mathrm{Q} 1$ & $\mathrm{Q} 2$ & $\mathrm{Q} 3$ & $\mathrm{Q} 4$ & $\mathrm{Q} 5$ & $\mathrm{Q} 6$ & $\mathrm{Q} 7$ & $\mathrm{Q} 8$ & $\mathrm{Q} 9$ \\
\hline$\widetilde{Z}_{11}$, child qualities & -0.066 & -0.022 & 0.004 & -0.033 & -0.013 & $\mathbf{- 0 . 0 3 6 * *}$ & $\mathbf{- 0 . 0 3 8 ^ { * * }}$ & $\mathbf{- 0 . 0 4 5 *}$ & $\mathbf{- 0 . 0 6 9 *}$ \\
& $(0.047)$ & $(0.029)$ & $(0.021)$ & $(0.019)$ & $(0.019)$ & $\mathbf{( 0 . 0 1 8 )}$ & $\mathbf{( 0 . 0 1 9 )}$ & $\mathbf{( 0 . 0 2 5 )}$ & $\mathbf{( 0 . 0 3 4 )}$ \\
$\widetilde{Z}_{12}$, child qualities & -0.064 & -0.032 & $-0.075^{* *}$ & -0.033 & 0.004 & 0.027 & 0.035 & 0.060 & $0.098^{*}$ \\
& $(0.072)$ & $(0.045)$ & $(0.033)$ & $(0.029)$ & $(0.029)$ & $(0.027)$ & $(0.029)$ & $(0.038)$ & $(0.053)$ \\
$\widetilde{Z}_{13}$, child qualities & 0.030 & -0.001 & -0.002 & -0.011 & -0.005 & 0.005 & 0.008 & 0.002 & 0.002 \\
& $(0.033)$ & $(0.021)$ & $(0.015)$ & $(0.014)$ & $(0.014)$ & $(0.013)$ & $(0.014)$ & $(0.018)$ & $(0.024)$ \\
$\widetilde{Z}_{2}$, civic capital & 0.088 & 0.042 & 0.027 & -0.005 & 0.017 & $\mathbf{0 . 0 5 9 * *}$ & 0.035 & 0.042 & 0.019 \\
& $(0.074)$ & $(0.046)$ & $(0.033)$ & $(0.030)$ & $(0.030)$ & $\mathbf{( 0 . 0 2 8 )}$ & $(0.030)$ & $(0.039)$ & $(0.054)$ \\
Pseudo R $\mathrm{R}^{2}$ & & & & & & & & & \\
Constant & 0.155 & 0.151 & 0.160 & 0.164 & 0.170 & 0.175 & 0.179 & 0.181 & 0.177 \\
& -2.952 & -1.488 & -0.630 & 0.174 & 1.047 & 0.686 & 1.446 & 2.194 & 2.891 \\
& $(3.070)$ & $(1.905)$ & $(1.393)$ & $(1.240)$ & $(1.240)$ & $(1.171)$ & $(1.240)$ & $(1.614)$ & $(2.246)$ \\
\hline \hline
\end{tabular}

Notes: The symbols $*{ }^{* *}$ and $* * *$ denote significance at the $10 \%, 5 \%$ and $1 \%$ significance level, respectively. The numbers in bold indicate that the coefficient associated to a cultural variable is statistically significant when not simultaneously controlling for the four cultural variables in the estimates but only for that cultural variable. The estimates include the following additional controls: Respondent's final education, ethnic number of children, ethnic men and women final educational levels, occupational dummies, age, Age squared, gender, per capita family income, number of own children in the family under 6, self-reported health, marital status, immigrant status of spouse, employment and education status of spouse, 50 state indicators, 3 metro indicators (urban, rural, metro) and year effects. Family income is converted into constant-1995 dollars prior to polling across years. 
Table 12. Robustness check I: Estimated effects by mother's birth place

\begin{tabular}{|c|c|c|c|c|}
\hline & Education & "Work & Occup. & Log. Wage \\
\hline \multirow[t]{2}{*}{$\widetilde{Z}_{11}$, same country } & $-0.363 * * *$ & 0.064 & $-0.200 * * *$ & $-0.063^{* *}$ \\
\hline & $(0.099)$ & $(0.054)$ & $(0.071)$ & $(0.024)$ \\
\hline \multirow{2}{*}{$\widetilde{Z}_{11}$, USA mother } & $-0.200^{* *}$ & -0.007 & -0.050 & 0.007 \\
\hline & $(0.079)$ & $(0.046)$ & $(0.063)$ & $(0.032)$ \\
\hline \multirow{2}{*}{$\widetilde{Z}_{11}$, other country } & $-0.171^{*}$ & -0.034 & -0.026 & 0.006 \\
\hline & $(0.089)$ & $(0.094)$ & $(0.068)$ & $(0.055)$ \\
\hline \multirow{2}{*}{$\widetilde{Z}_{12}$, same country } & $0.337 * * *$ & -0.109 & $0.214^{* *}$ & -0.028 \\
\hline & $(0.092)$ & $(0.085)$ & $(0$. & $(0.030)$ \\
\hline \multirow{2}{*}{$\widetilde{Z}_{12}$, USA mother } & $0.259 * *$ & -0.067 & 0.0 & -0.003 \\
\hline & $(0.107)$ & $(0.062)$ & $(0.079)$ & $(0.023)$ \\
\hline \multirow{2}{*}{$\widetilde{Z}_{12}$, other country } & $0.376 * *$ & -0.097 & 0.081 & 0.010 \\
\hline & $(0.152)$ & $(0.106)$ & $(0.089)$ & $(0.051)$ \\
\hline \multirow{2}{*}{$\widetilde{Z}_{13}$, same country } & -0.117 & -0.012 & -0.077 & -0.009 \\
\hline & $(0.096)$ & $(0.045)$ & )$(0$. & $(0.018)$ \\
\hline \multirow[t]{2}{*}{$\widetilde{Z}_{13}$, USA mother } & -0.000 & 0.027 & 0.002 & 0.003 \\
\hline & $(0.059)$ & $(0.027)$ & $(0.0$ & $(0.022)$ \\
\hline \multirow[t]{2}{*}{$\widetilde{Z}_{13}$, other country } & -0.074 & 0.117 & $-0.107^{* *}$ & -0.010 \\
\hline & $(0.091)$ & $(0.084)$ & $(0.048)$ & $(0.049)$ \\
\hline \multirow[t]{2}{*}{$\widetilde{Z}_{2}$, same country } & $0.588 * * *$ & 0.004 & 0.069 & 0.029 \\
\hline & $(0.109)$ & $(0.055)$ & $(0.090)$ & $(0.024)$ \\
\hline \multirow{2}{*}{$\widetilde{Z}_{2}$, USA mother } & $0.232^{*}$ & -0.063 & 0.129 & -0.020 \\
\hline & $(0.133)$ & $(0.044)$ & $(0.099)$ & $(0.031)$ \\
\hline \multirow[t]{2}{*}{$\widetilde{Z}_{2}$, other country } & $0.594 * * *$ & $0.223^{*}$ & 0.106 & 0.030 \\
\hline & $(0.172)$ & $(0.118)$ & $(0.119)$ & $(0.064)$ \\
\hline
\end{tabular}

Notes: The symbols $*,{ }^{* *}$ and $* * *$ denote significance at the $10 \%, 5 \%$ and $1 \%$ significance level, respectively. The numbers in bold indicate that the coefficient associated to a cultural variable is statistically significant when not simultaneously controlling for the four cultural variables in the estimates but only for that cultural variable. I) The outcome variables in the first column is the respondent's years of education. In the second and third columns the outcome variables are dummies indicating whether the respondent works and whether, conditioned on working, his occupational status correspondes to the first two major occupational categories, respectively. The outcome variable in the last column is the log of respondets' wage and salary earnings. Thus, the table reports probit marginal effects in the second and third columns and OLS estimates in the first and fourth columns. II) The estimates include the following additional controls: Respondent's final education, age, Age squared, gender, per capita family income, number of own children in the family under 6 , self-reported health, marital status, immigrant status of spouse, employment and education status of spouse, 50 state indicators, 3 metro indicators (urban, rural, metro) and year effects. Family income is converted into constant-1995 dollars prior to polling across years. In addition, estimates in the last column also control for respondent's occupation. 
Table 13. Robustness check II: Omitting respondents from Mexican ancestry

\begin{tabular}{|c|c|c|c|c|}
\hline & Education & Work & Occup. & Log. Wage \\
\hline$\widetilde{Z}_{11}$, child qualitie & $\begin{array}{l}\text { S }-0.317^{* * * *} \\
(0.055)\end{array}$ & $\begin{array}{l}0.024 \\
(0.034)\end{array}$ & $\begin{array}{l}-0.100 * * \\
(0.041)\end{array}$ & $\begin{array}{l}-0.031^{* *} \\
(0.014)\end{array}$ \\
\hline$\widetilde{Z}_{12}$, child qualitie & $\begin{array}{c}0.447 * * * \\
(0.085)\end{array}$ & $\begin{array}{l}-0.072 \\
(0.067)\end{array}$ & $\begin{array}{l}0.134^{*} \\
(0.069)\end{array}$ & $\begin{array}{l}0.000 \\
(0.020)\end{array}$ \\
\hline$\widetilde{Z}_{13}$, child qualitie & $\begin{array}{r}-0.058 \\
(0.044)\end{array}$ & $\begin{array}{l}0.011 \\
(0.021)\end{array}$ & $\begin{array}{l}-0.022 \\
(0.034)\end{array}$ & $\begin{array}{l}0.014^{*} \\
(0.008)\end{array}$ \\
\hline$\widetilde{Z}_{2}$, civic capital & $\begin{array}{l}0.314^{* * *} \\
(0.111)\end{array}$ & $\begin{array}{l}-0.012 \\
(0.102)\end{array}$ & $\begin{array}{l}0.096 \\
(0.152)\end{array}$ & $\begin{array}{l}0.026 \\
(0.034)\end{array}$ \\
\hline N.obs & 2988 & 2973 & 2382 & 2183 \\
\hline
\end{tabular}

Notes: The symbols $*{ }^{* *}$ and ${ }^{* * *}$ denote significance at the $10 \%, 5 \%$ and $1 \%$ significance level, respectively. The numbers in bold indicate that the coefficient associated to a cultural variable is statistically significant when not simultaneously controlling for the four cultural variables in the estimates but only for that cultural variable. I) The outcome variables in the first column is the respondent's years of education. In the second and third columns the outcome variables are dummies indicating whether the respondent works and whether, conditioned on working, his occupational status correspondes to the first two major occupational categories, respectively. The outcome variable in the last column is the log of respondets' wage and salary earnings. Thus, the table reports probit marginal effects in the second and third columns and OLS estimates in the first and fourth columns. II) The estimates include the following additional controls: Respondent's final education, age, Age squared, gender, per capita family income, number of own children in the family under 6 , self-reported health, marital status, immigrant status of spouse, employment and education status of spouse, 50 state indicators, 3 metro indicators (urban, rural, metro) and year effects. Family income is converted into constant-1995 dollars prior to polling across years. In addition, estimates in the last column also control for respondent's occupation. 